\title{
Nanofiltration for separation and purification of saccharides from biomass
}

\author{
Xianhui Li ${ }^{1}$, Sheng Tan ${ }^{2}$, Jianquan Luo $(\bowtie)^{2}$, Manuel Pinelo $(\bowtie)^{1}$ \\ 1 Process and Systems Engineering Center (PROSYS), Department of Chemical and Biochemical Engineering, Technical University of Denmark, \\ DK-2800 Lyngby, Denmark \\ 2 State Key Laboratory of Biochemical Engineering, Institute of Process Engineering, University of Chinese Academy of Sciences, \\ Chinese Academy of Sciences, Beijing 100190, China
}

(C) Higher Education Press 2021

\begin{abstract}
Saccharide production is critical to the development of biotechnology in the field of food and biofuel. The extraction of saccharide from biomass-based hydrolysate mixtures has become a trend due to low cost and abundant biomass reserves. Compared to conventional methods of fractionation and recovery of saccharides, nanofiltration (NF) has received considerable attention in recent decades because of its high selectivity and low energy consumption and environmental impact. In this review the advantages and challenges of NF based technology in the separation of saccharides are critically evaluated. Hybrid membrane processes, i.e., combining $\mathrm{NF}$ with ultrafiltration, can complement each other to provide an efficient approach for removal of unwanted solutes to obtain higher purity saccharides. However, use of NF membrane separation technology is limited due to irreversible membrane fouling that results in high capital and operating costs. Future development of NF membrane technology should therefore focus on improving material stability, antifouling ability and saccharide targeting selectivity, as well as on engineering aspects such as process optimisation and membrane module design.
\end{abstract}

Keywords saccharides, nanofiltration membrane, hybrid membrane process, biomas

\section{Introduction}

Biomass is an abundant and renewable resource which can be used for energy production by direct combustion [1]. In general, the biomass feedstocks include various wood residues, agricultural residues, and crops grown specifi-

Received May 23, 2020; accepted September 22, 2020

E-mails: jqluo@ipe.ac.cn (Luo J), mp@kt.dtu.dk (Pinelo M) cally for nonfood etc. [2]. The estimated annual production of biomass in nature is about 170 billion tons [3]. The annually renewable biomass production includes saccharides (75\%), lignin (20\%), and other substances such as fats (oils) and proteins (5\%) [4]. Saccharides are important feedstocks that are used in the food, cosmetic, pharmaceuticals, oil drilling and fermentations industries $[2,5,6]$. As demand for saccharides in various industrial applications has grown, there has been increased interest in saccharides extraction from biomass. According to the definition of the World Health Organization, the saccharides can be classified into four types: monosaccharides (degree of polymerization $(\mathrm{DP})=1$ ), disaccharides $(\mathrm{DP}=$ $2)$, oligosaccharides $(\mathrm{OS})(\mathrm{DP}=3-9)$, and polysaccharides (DP $>10)$ on the basis of the chemical structure and DP (Table 1) [7]. 1) Monosaccharides. The main monosaccharides are glucose, fructose, and xylose. Some rare saccharides with high-value or potential commercial applications are dextrose, mannose, galactose, arabinose, and rhamnose [8]. These were produced from agricultural lignocellulosic biomass by biological or thermochemical processes involving several steps, including separation, pre-concentration and purification. The purification process usually needs neutralization, filtration, and precipitation by addition of an organic solvent [9]; 2) Disaccharides. These refer to natural and untreated white sugar, mainly containing sucrose. These are directly extracted from plants (such as sugar cane or sugar beet) by traditional techniques including pre-treatment, extraction, clarification and/or purification, evaporation, crystallization, and centrifugal separation. Other disaccharides include maltose, trehalose, and cellobiose; 3) OS. The OS, classified as prebiotic, are carbohydrates containing approximately 20 monomers [10]. Currently the wellrecognized prebiotics include certain fructooligosaccharides (FOS), galactooligosaccharides (GOS), xylooligosaccharides (XOS), isomaltooligosaccharides, lactulose, 
raffinose, and a number of other compounds. They are produced by enzymatic trans-glycosylation or controlled degradation reaction (such as hydrolysis from hemicelluloses). For example, the commercial GOS products are manufactured by the enzymatically catalysed reaction of concentrated lactose solution with $\beta$-galactosidase [11]. The main problem is that the GOS solution is complicated and consists of many saccharides with different structures; 4) Polysaccharides. The widely used polysaccharides are alginate, dextran, cellulose and chitosan (CS).

However, several challenges need to be addressed during the saccharide production process: 1) the primary saccharides are unstable under the biomass hydrolysis and extraction conditions because saccharides are easily dehydrated and further transformed into degradation products with low molecular weight, such as acetic acid, formic acid, and furfural; 2) most by-products are inhibitors of the fermentation or enzymatic catalytic process [12] and, importantly, the concentration of raw saccharide is very low [10] while the by-products are also enriched during concentration step; 3) products and byproducts with similar chemical structure and physicochemical properties are usually mixed together and are difficult to separate; 4) fractionation of saccharide affects the following processing steps and thus limits the scale of production, the efficiency of saccharide crystallization, and even the quality of raw saccharide production.

To obtain high-quality saccharide, several separation techniques have been applied in the saccharides purification process, including vacuum evaporation [13], adsorption [14], precipitation by ethanol [15], ion exchange [16], chromatography [17] and membrane separation technology $[18,19]$, as shown in Table 2. In comparison, membrane technology, i.e., nanofiltration (NF), is a promising technology for separation and purification of saccharides due to low energy consumption, reduced environmental impact and, in particular, the maintenance of the intrinsic properties of the product during the separation process [20]. NF has been widely applied for saccharide extraction from mixtures based on both steric hindrance and Donnan exclusion. For most neutral saccharides, their mass transports through NF membranes are controlled by convection and diffusion [21]. For other charged saccharides, such as pectate oligosaccharides (POS), their separation efficiency is influenced by the membrane surface charge properties. However, NF-based separation and purification of saccharides from biomass still face the challenges of low concentration of target saccharide, complex composition and severe membrane fouling. To our best knowledge, there are very few comprehensive reviews concerning NF-based separation technologies for saccharides extraction, especially with regard to the challenges and potential opportunities associated with NF-based separation processes.

In this paper, we review the development of NF membrane technology for the separation of saccharides

Table 1 Summary of main commercial saccharides

\begin{tabular}{|c|c|c|c|c|}
\hline$\overline{\text { Saccharide type }}$ & Product & Production method & Application & $\overline{\text { Ref. }}$ \\
\hline \multirow[t]{5}{*}{ Monosaccharides } & Glucose & Extraction, hydrolysis & Food additive, fermentation feedstock & [2] \\
\hline & Fructose & Extraction, hydrolysis & Sweetener & [22] \\
\hline & Xylose & Hydrolysis & $\begin{array}{c}\text { Production of xylitol, sugar substitute, starting material } \\
\text { for the synthesis of drugs, synthesis of L-ribofuranose } \\
\text { derivatives }\end{array}$ & [6] \\
\hline & Arabinose & Hydrolysis & $\begin{array}{l}\text { Culture medium, natural sweetener, intermediate raw } \\
\text { material in pharmaceuticals }\end{array}$ & [23-25] \\
\hline & Galactose & Hydrolysis & Food additive & {$[26,27]$} \\
\hline \multirow[t]{2}{*}{ Disaccharides } & Sucrose & Extraction & Food additive, fermentation feedstock & [2] \\
\hline & Maltose & Hydrolysis & Sweetener, fermentation processes & [28] \\
\hline \multirow[t]{5}{*}{ OS } & Fructooligosaccharides & Biosynthesis, hydrolysis & $\begin{array}{l}\text { Prebiotics (non-cariogenic diabetic-friendly products), an } \\
\text { alternative sweetener }\end{array}$ & [29] \\
\hline & Galactooligosaccharides & Biosynthesis & Prebiotics, enhancing the organoleptic quality of foods & [30] \\
\hline & XOS & Hydrolysis & Prebiotics, enhancing the organoleptic quality of foods & [31] \\
\hline & Isomaltooligosaccharides & Hydrolysis, biosynthesis & Prebiotics, enhancing the organoleptic quality of foods & [30] \\
\hline & Raffinose & Hydrolysis & $\begin{array}{l}\text { Starting material for synthesis of sucralose, used in foods } \\
\text { to reduce calories }\end{array}$ & [30] \\
\hline \multirow[t]{3}{*}{ Polysaccharides } & Alginate & Extraction & $\begin{array}{l}\text { Immobilization matrix, micro-encapsulation matrix, } \\
\text { hypo-allergic wound-healing tissue }\end{array}$ & [32] \\
\hline & Dextran & Extraction, biosynthesis & Drug delivery application & [33] \\
\hline & Cellulose & Extraction & $\begin{array}{l}\text { Healing of burns or surgical wounds, non-digestible } \\
\text { fibres }\end{array}$ & [32] \\
\hline
\end{tabular}


Table 2 Obtainment of saccharides from different feedstocks

\begin{tabular}{|c|c|c|c|c|}
\hline Feedstock & Product & Production method & Purification method & Ref. \\
\hline Molasses & Sucrose & $\begin{array}{l}\text { Separation of sucrose from } \\
\text { molasses }\end{array}$ & $\begin{array}{l}\text { Ultrafiltration (UF) and NF membranes (UF10 kDa, UF5 kDa, } \\
\qquad \mathrm{N} 30 \mathrm{~F})\end{array}$ & {$[34]$} \\
\hline Birchwood xylan & XOS & Enzymatic hydrolysis & Size-exclusion and ion-exchange & {$[35]$} \\
\hline Wheat & XOS & Enzymatic hydrolysis & $\begin{array}{l}\text { Graded ethanol precipitation or } \\
\text { UF membranes with different pore sizes }\end{array}$ & [36] \\
\hline Rice husks & XOS & Hydrothermal treatment & $\begin{array}{c}\text { Evaporation, ethyl acetate extraction, solvent precipitation, } \\
\text { ion-exchange }\end{array}$ & [37] \\
\hline Biomass & XOS & $\begin{array}{l}\text { Steam explosion and subsequent } \\
\text { hydrolysis }\end{array}$ & Ion-exchange & [38] \\
\hline $\begin{array}{l}\text { Xylose mother } \\
\text { liquor }\end{array}$ & L-arabinose & Bioconversion & $\begin{array}{l}\text { Decoloration with activated carbon, ion-exchange resin } \\
\text { columns for removing metal ions }\end{array}$ & [23] \\
\hline Seaweed sample & Galactose & Hydrolysis, fermentation & Activated charcoal treatment and over-liming & [39] \\
\hline Sugarcane bagasse & Glucose and XOS & Hydrolysis, fermentation & Methanol precipitation & [40] \\
\hline Sugar beet pulp & Pectins & Hydrolysis and extraction & Acid, ethanol extractions, centrifugation & [41] \\
\hline Cane molasses & OS, D-fructose & Enzymatic bioprocessing & Extraction & [42] \\
\hline
\end{tabular}

from biomass and summarize the significant advances in the applications of NF. Furthermore it provides an insight into the mechanisms of solutes transport and membrane fouling as well as membrane cleaning strategies. Finally, the challenges of membrane separation technology in the saccharide industry and the potential opportunities for improvement are discussed.

\section{NF for saccharide separation}

$\mathrm{NF}$ is a well-established separation process in fermentation and biotechnology, which is widely applied in purifying saccharides from different stocks (Table 3) [21].

\subsection{Separation of monosaccharides and disaccharides}

The separation of different monosaccharides is still challenging due to their similar molecule sizes, structures, and charges. Although NF enables separation of monosaccharides from disaccharides, or removal of monosaccharides and disaccharides from high weight saccharides such as OS based on a size sieving mechanism, the separation of different monosaccharides is not easy. To effectively separate a pentose (xylose) from a hexose (glucose), Sjöman et al. [43] investigated the effect of types of NF membranes (NF270 with MWCO of 150 $200 \mathrm{Da}$, Desal-5 DK and Desal-5 DL with MWCO of 150 $300 \mathrm{Da})$ on xylose production yield. The results showed that all three membranes enhanced the mass ratio of xylose to glucose at least two fold because of the large size of glucose molecule. However, the best NF membrane achieved a maximum xylose/glucose separation factor of only 3.3 because the molecular weight difference between these sugars is only $30 \mathrm{Da}$. In order to enhance the separation of xylose/glucose mixtures, Morthensen et al. [52] established an enzymatic process for converting glucose (180 Da) to gluconic acid (196 Da) followed by separation of xylose from gluconic acid by NF; this process increased the separation factor of the NF270 membrane to 34 due to a stronger size sieving and additional charge effect.

On the other hand, the relative molecular weight of disaccharides $\left(\sim 300-360 \mathrm{~g} \cdot \mathrm{mol}^{-1}\right)$ is similar with that of monosaccharides (e.g., pentose and hexose $\sim 150$ $180 \mathrm{~g} \cdot \mathrm{mol}^{-1}$ ). Highly efficient NF separation thus requires a suitable and accurate membrane pore size. For example, a dense membrane with MWCO of 100 Da can completely retain both solutes. Another looser membrane with MWCO of 300 Da was able to achieve more than $99 \%$ retention of disaccharides but allowed monosaccharides pass partially with a reported retention of 68\% [53]. Obtaining separation factors of monosaccharides and disaccharides depends not only on the physicochemical properties of the NF membrane but also on the operation conditions [54]. Therefore optimization of operation conditions, such as feed flow rate, transmembrane pressure and $\mathrm{pH}$, can help improve the separation factor. Himstedt et al. [55] showed that the separation factor of glucose and sucrose can be enhanced through optimizing operating $\mathrm{pH}$. The reason is that $\mathrm{pH}$ affects the membrane surface charge through protonation or deprotonation of grafted polymer chains, which leads to variation of hydrogen bonding interaction between the sugar molecules and the polymer chains. Luo et al. [56] found that a DL membrane with MWCO of of 150-300 Da had a sucrose retention of $96 \%$ and a reducing sugar retention of $5 \%$ when the operating temperature was increased to $60^{\circ} \mathrm{C}$ since high temperature induces pore size change and enhances solute diffusivity. In addition, they claimed that high sugar concentration, 


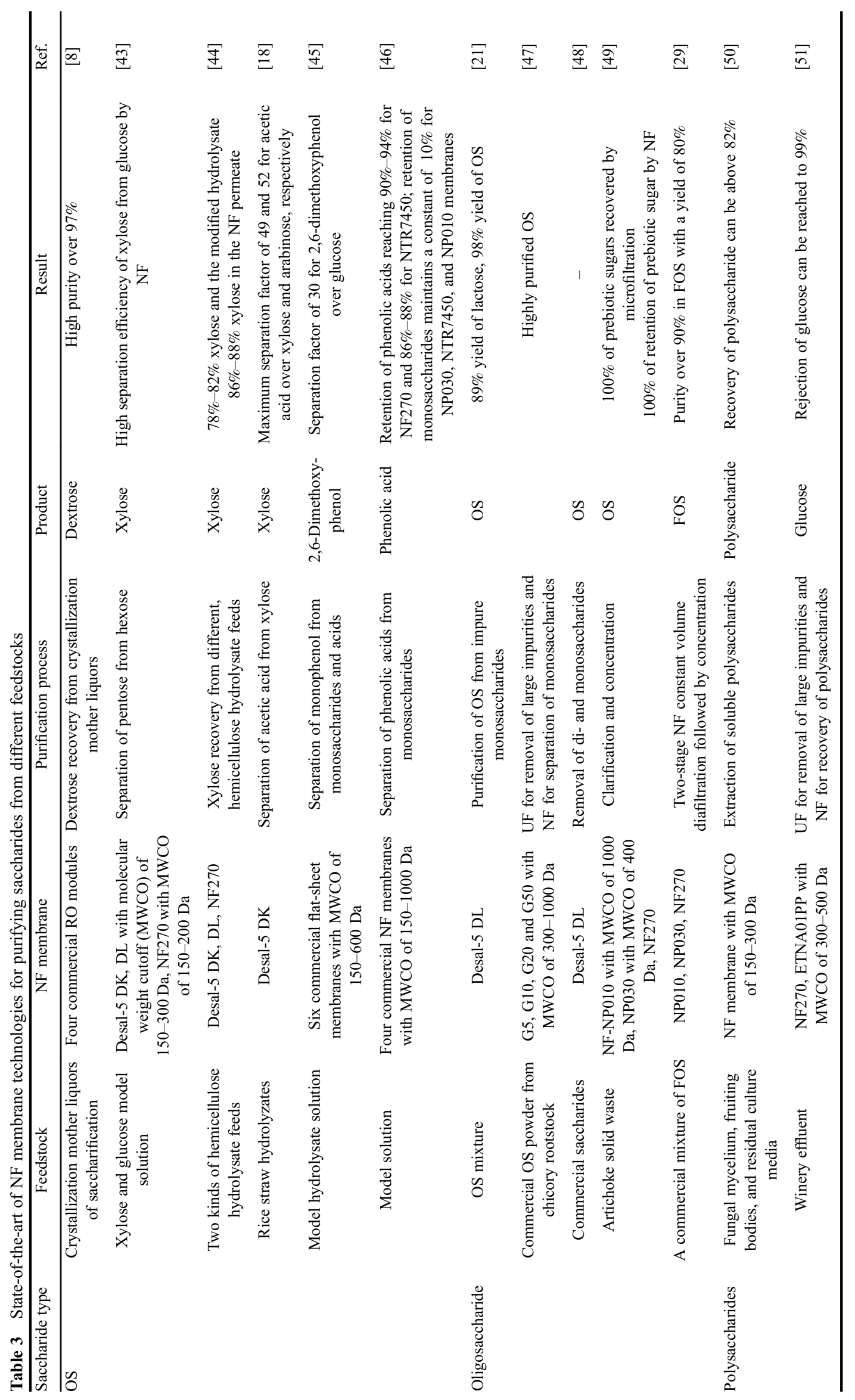


low permeate flux (below $15 \mathrm{~L} \cdot \mathrm{m}^{-2} \cdot \mathrm{h}^{-1}$ ), and high temperature $\left(55-60{ }^{\circ} \mathrm{C}\right)$ led to a low retention of monosaccharides because of diffusive mass transfer control, which was beneficial for the separation of monosaccharides and disaccharides by NF. In addition, in comparison with the feed stream containing a single solute-water solution, the separation factor might be slightly altered, probably due to solute-solute, solutemembrane surface interaction [57]. Use of NF to separate monosaccharides and disaccharides from saccharides with large molecular weights is also a very common application due to the high separation selectivity, especially the purification of OS.

\subsection{Separation of OS}

OS are beneficial to human health as functional food ingredients. Owing to a lack of natural sources with high concentrations of OS and difficulty of synthesis, several enzymatic trans-glycosylation or the controlled degradation reactions have been employed to produce high quantities of OS. OS can be categorized into FOS, XOS, GOS and POS based on differences of resources [58]. No matter which type is in focus, the reaction mixture consists of OS, other low molecular weight sugars, and unreacted feedstock. NF has been conducted as a mature industrialscale technology for the purification and concentration of OS mixtures to obtain high purity OS. A combination of UF and NF has also been successfully used to recover natural OS [10]. As presented in Fig. 1, in this integrated process, the UF process is used to separate polysaccharide and protein together with other impurities and the permeate from UF is subsequently processed with NF. The OS is concentrated in the retentate and the smaller monosaccharides and disaccharides are removed to the permeate. Grandison et al. [59] demonstrated the feasibility of separating monosaccharides from mixed disaccharides and OS using a loose NF membrane with MWCO of $1 \mathrm{kDa}$. During the NF purification of a commercial OS

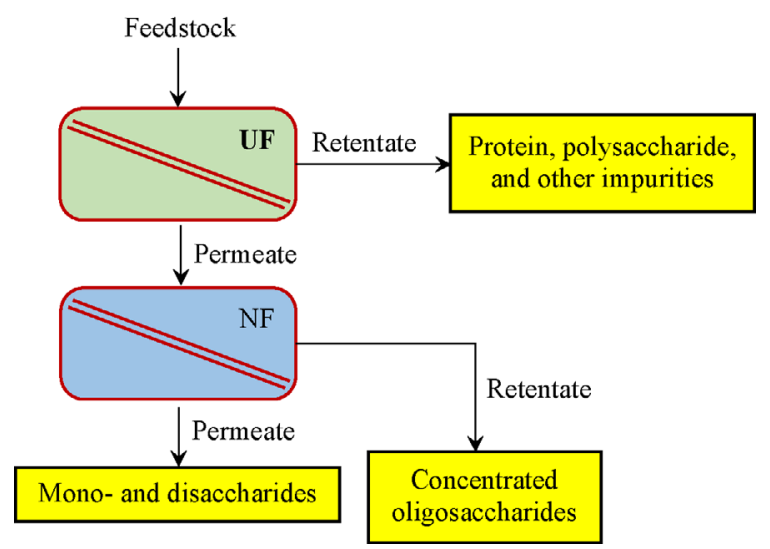

Fig. 1 Schematic diagram of the hybrid UF-NF membrane process for OS extraction. mixture, the yield of monosaccharides and both disaccharides and OS reached $19 \%$ and $88 \%$, respectively, indicating the efficient removal of the monosaccharides. A suitable NF membrane and optimum operating conditions are important to achieve the maximum recovery efficiency for different types of OS.

FOS formed by combination of several fructose moieties with sucrose have strong prebiotic effects. Kuhn et al. [29] proposed a two-stage UF-NF hybrid process to separate the FOS from the enzymatic conversion product of sugar cane molasses containing glucose, fructose, and sucrose. In the first stage, the conversion product was filtered by UF membrane and then through a concentration step to achieve a high purity of FOS; in the second stage, the NF permeate was concentrated to increase the total yield. A purity of $90 \%$ FOS with yield of around $80 \%$ was obtained. However, high sugar content easily results in propagation of micro-organism contamination. Low-temperature filtration at $5{ }^{\circ} \mathrm{C}$ can solve this challenge and improve the $\mathrm{OS}$ recovery yield [11].

XOS are novel prebiotic OS that can act as soluble dietary fibers. Xylan extraction from plant hemicelluloses is the first step for producing XOS from hydrolysis treatment by acid and alkali, or by enzymatic methods. To increase the separation efficiency, NF technology is incorporated into the conventional downstream processing for purification of XOS. XOS recovery of $74.5 \%$ was achieved by using a combination of UF $(50 \mathrm{kDa})$ and NF $(1 \mathrm{kDa})$ [60]. To increase the XOS recovery, another NF membrane (500 Da) was used to achieve a high recovery of $95 \%$ and purity of $99 \%$ at operating pressure of 20 bar and temperature of $50{ }^{\circ} \mathrm{C}[61]$.

GOS are a good low calorie sweetener, and can also be purified and concentrated by a hybrid UF and NF process [47]. Montesdeoca et al. [62] evaluated the potential of hybrid UF-NF process for continuous OS purification in a pilot plant. A dynamic model was established on the basis of the film theory. The model predicted a maximum purity of $46.7 \%$ and $94.9 \%$ for GOS and FOS, respectively, which is higher than experimental results (purity of $40.4 \%$ for GOS and $84 \%$ for FOS) by using NF membrane with MWCO of 1-2 kDa. These results confirmed that NF technology not only removes small molecular weight molecules such as monosaccharides and disaccharides, but also separates different kinds of OS.

POS have effective immune modulating properties. Based on the charge characteristics of POS, charged membranes are required for the separation of POS. Almost all monosaccharides permeated through the NF membrane (400 Da) while 60\%-80\% disaccharides and higher saccharides were rejected in the retentate and were used as final product [63]. The rejection of charged POS by NF reached $80 \%$, whereas no retention of the neutral FOS was observed during use of the charged NF membrane $(1500 \mathrm{Da})$, which indicated that electrostatic repulsion was the dominate mechanism [64]. 


\subsection{Separation of polysaccharides}

Polysaccharides are a significant component of fungal cells and have important medicinal and nutritional properties. Polysaccharides are generally extracted from fruiting bodies and fungal mycelium by bioreactors. The following recovery and concentration of polysaccharides from pretreatment solutions was successfully carried out using NF that can separate low molecular weight polysaccharides [65]. A polysaccharide yield of $85 \%-92 \%$ could be achieved for extraction from mycelium and fruiting bodies [50]. A NF membrane exhibited a 99\% rejection of polysaccharide from a winery effluent, further showing the potential for large-scale application [51].

However, permeate flux was shown to be reduced significantly with increasing filtration time over the course of the process because polysaccharide was easily adsorped on the membrane surface and even the pore walls, leading to irreversible fouling $[66,67]$. Backflushing could effectively reduce reversible fouling but not irreversible fouling [68]. Compared with flat sheet NF membranes, it is easier to conduct in-line cleaning with tubular membranes. For example, alkaline cleaning agents can help in cleaning the polarized gel layer because polysaccharides are rich of $-\mathrm{COOH}$ groups. The hydrophilic modification of the membrane surface by doping or grafting functional hydrophilic materials, such as graphene oxide [69], is an alternative for reducing adsorption of polysaccharides.

\subsection{Isolation of sugar from non-sugar components}

NF membrane technology has been used in the sugar industry as a key step in clarification and purification, which affects sugar crystallization and the quality of raw sugar production [56]. Minimizing sucrose retention and simultaneously maintaining a high decolorization efficiency are significant challenges because complex and high levels of impurities would result in serious membrane fouling. To address the trade-off between sucrose recovery and color removal, Luo et al. [70] proposed a hybrid UFNF membrane process in which a tight UF membrane was used for decolorization of cane juice with a removal rate of $95 \%$. Similarly, $77 \%-89 \%$ color removal rate was achieved by a tight UF in the decoloration of sugarcane molasses [71]. Subsequently the light-colored permeate was injected into NF to recover sucrose. However, in this procedure the pigments in sugarcane molasses would adsorb on the membrane surface and pore walls, resulting in irreversible fouling and thus reducing the efficiency of sucrose recovery [72]. To control this fouling on the surface of the NF membrane, a nonpolar resin was used to remove pigments at the front of the NF process $[73,74]$, the NF operating pressure was decreased by $50 \%$ and the resulting permeability increased by $10 \%$.

Removal of by-product is another problem in sugar purification. Most by-products are low molecular weight organic compounds, including furfural, acetic acid, 5hydroxymethylfurfural (5-HMF) and formic acid. NF is the best choice for separating the sugar from small organic compounds because of its high selectivity for small molecular. Kim et al. [27] proposed a two-stage membrane process by combining the NF membrane with electrodialysis for the separation of levulinic acid (LA), 5-HMF, and galactose. NF is first used to remove LA and 5-HMF from galactose solution produced by the hydrolysis of agarose. The result showed that $62 \%$ of LA and $91 \%$ of 5 HMF could be removed from agarose hydrolysate, while galactose was almost completely rejected by NF, thus significantly decreasing the microbial toxicity of the hydrolysate. Gautam and Menkhaus [75] reported the ability of NF membranes to separate sugars from inhibitors (e.g., furans, mineral and organic acids, and phenolic compounds) in real biomass enzymatic hydrolysates and achieve a high yield of sugar at nearly $93 \%$. Weng et al. [76] separated acetic acid from xylose using a Desal-5 DK NF membrane. The optimum retentions of acetic acid and xylose were $90 \%$ and $81 \%$, respectively, with a maximum separation factor of 5.4 at an operating pressure of $24.5 \mathrm{bar}$ and $\mathrm{pH}$ of 2.9 .

In industrial sugar production, another challenge is that a large amount of the total sugar loss occurs in the final molasses because melassigenic ions in the non-sugar organic material inhibit the crystallization of sucrose. The presence of melassigenic ions not only leads to lower sugar yield but also to a higher cost of sugar extraction because the alkali and alkaline metal ions grip sugar in the molasses and prevent sugar from being recovered in crystalline form. The melassigenic effect of the ions decreases in the order of $\mathrm{K}^{+}>\mathrm{Na}^{+}>\mathrm{Ca}^{2+}>\mathrm{Mg}^{2+}$. More sugars could be recovered with decreasing concentration of these ions [77]. $\mathrm{NF}$ therefore plays a vital role in the recovery of sugar through the simultaneous removal of salts and pigments [78].

\section{Mass transport mechanism and model}

The main mechanism of NF for separation of neutral solutes is size exclusion. The "low weight molecule" passes through the NF membrane, while the "larger weight molecule" is retained in the feed solution. With NF membranes used in the fractionation of different saccharides from a mixed solution, the "permeate solute" is low molecular weight saccharide, such as glucose, xylose and sucrose, or the non-saccharide components (inorganic salt, organic acid). Therefore modelling the performance of a NF membrane could deepen understanding of saccharide transport mechanisms and of the interaction between significant operating parameters [79-81]. 


\subsection{Mass transport mechanisms}

Since most saccharides are neutral molecules in aqueous solution, mass transport through NF membranes is controlled by convection and diffusion [82]. The basic models for description of flux variation include the Spiegler-Kedem model and the Extended Nernst-Planck equation [83]. The application of these models relies on the membrane transport parameters. According to the Spiegler-Kedem model, for example, NF membranes are characterized by three transfer coefficients: solute permeability $P_{\mathrm{s}}$, reflection coefficient $\sigma$, and pure water permeability $L_{\mathrm{P}}$ [84]. The transport parameters of low molecular weight saccharides, like glucose, sucrose and xylose, can be determined by experiments because high purity product can easily be obtained.

The transport parameters of large molecular weight saccharides, such as OS, cannot be directly measured by experiments due to lack of high purity OS. However, these OS transport parameters might be calculated using the experimental results of low molecular weight saccharides. For example, Li et al. [85] proposed a method for predicting OS transport parameters based on the permeability and reflection coefficients of glucose and sucrose. They found that the single pore model does not fit all kinds of solutes in the multi-solute system. Hence the permeability of OS and low molecular weight saccharides needs to be calculated independently using the following equations:

$$
\begin{gathered}
R=1-\frac{K \phi}{1-(1-K \phi) \mathrm{e}^{-P e}}, \\
P e=\frac{K J}{D}\left(\frac{\Delta x}{A}\right)
\end{gathered}
$$

where $R$ is the filtration resistant, $K$ is the hindrance factor, $\phi$ is the porosity, $P e$ is the Peclet number, $J$ is the permeate flux, $D$ is the diffusivity of solute, $\Delta x$ is the length of membrane segment, and $A$ is the membrane area. As different molecular weight saccharides can be separated by NF membranes, the changes of resistance and the resulting osmotic pressure affecting the flux and rejection should be taken into account because of solute/membrane steric interactions. A model was developed by Kuhn et al. [29] to predict the variation of flux and rejection with filtration time. They found that the solute adsorption on the membrane is a crucial factor for determining the kinetic constant of adsorption, $k_{\mathrm{ads}, i}$, which represents a function of the molecular weights as shown in Fig. 2. There is a proportionality between the adsorption mass and the fouling resistance.

Solute is often assumed to be spherical-like inorganic ions in the above models. This assumption is suitable for inorganic ions because of their stable structures. However, the assumption is not suitable for saccharides because of

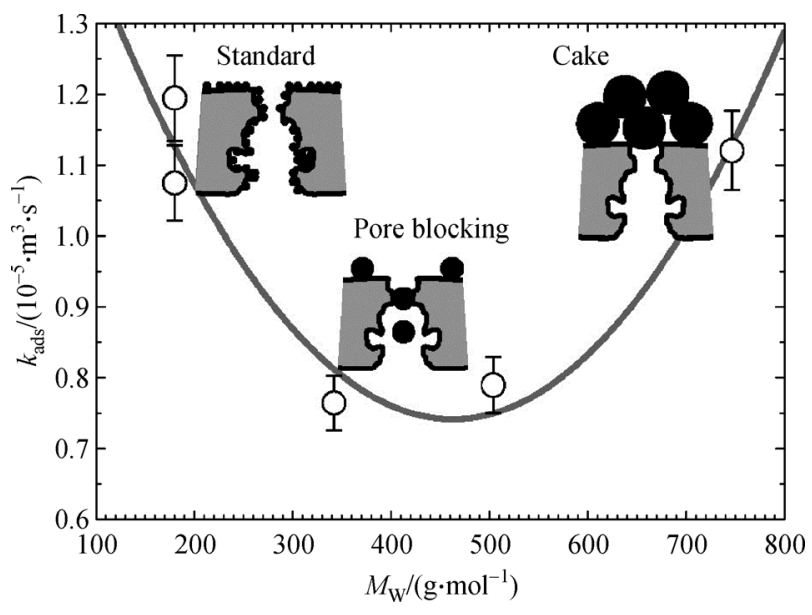

Fig. 2 Relationship of molecular weight to adsorption mechanisms. Reprinted with permission from Ref. [29], copyright 2010 Elsevier.

their non-uniform molecular weights. For example, branched solutes have a large distribution molecular weights. To solve this challenge, various hypotheses are used, such as the molecular width plot for branched effects [86] and the effects of molecular length and molecular width on steric partition factor [87]. Kiso et al. [88] investigated the separation performance of NF membranes for alcohols and saccharides. They found that molecular width played a major role in controlling solute permeation with membranes with small pores. The pore radii of NF membranes were calculated based on the non-spherical and spherical model by using the rejection data of glucose, sucrose and raffinose. The results revealed that the pore radii calculated by the nonspherical model were obviously larger than those calculated by the spherical model.

NF membranes suffer from serious biofouling during separation of saccharides. In addition to sterilization after operation, employing UV irradiation and sterile filtration [89] conducted at lower or higher temperatures are beneficial for mitigating potential microbial growth and biofouling. As mentioned above, membrane structure parameters and mass transfer properties can be predicted by combining theoretical calculations with experimental results. But the effect of temperature on mass transfer and membrane structure was not taken into account. Pruksasri et al. [11] therefore investigated the effects of temperature on NF performance in GOS purification using the Extended Nernst-Planck equation to elaborate the relationship between temperature and pore size of NF membranes. The results showed a linear increase of pore size radius $\left(r_{\mathrm{p}} \cong 0.0036 T+0.68\right)$ of $\mathrm{NF}$ membrane as operating temperature increased from $5{ }^{\circ} \mathrm{C}$ to $60{ }^{\circ} \mathrm{C}$. The pore size distribution of the membrane was enlarged with increase in temperature, leading to decrease of rejection. In addition, the temperature affected the diffusivity, chemical structure and concentration of individual saccharides. Similar results 
were observed by Bandini [90] in that the hydrodynamic coefficient of the solute was another adjustable parameter that is related to saccharide type. Although most saccharides are neutral molecules in aqueous solution, the presence of electrolyte can change the electric layer on the membrane surface, membrane pore size distribution and solute properties, which leads to increase of saccharide transfer due to solute dehydration induced by the electrolyte [91]. Diafiltration process is an effective technique to achieve both high purification rate and economically acceptable permeate flux, and thus it has been widely in food, beverage, and biotechnological industries to concentrate protein or to recover saccharides [92]. Especially, Wang et al. has proven that the diafiltration process by using NF membrane is a feasible process to concentrate $\mathrm{OS}$ and simultaneously remove $\mathrm{NaCl}$ from soybean whey wastewater [93].

\subsection{NF process models}

Modeling the filtration process of a pilot-scale NF system has played a critical role in promoting the application of $\mathrm{NF}$ in the real saccharide industry. Computational fluid dynamics was applied to simulate diafiltration performance (i.e., permeate concentration and permeability, etc.) with dilution water added during treatment of mixture of sucrose and inulin [94]. Simulations indicated that the recovery of sucrose was achieved to $99 \%$. In a single stage process, a model based on mass balance was developed to calculate the relationship between FOS purity and dilution water usage by NF under different operation modes [54]. The relationship between yield and purity was found to be independent of the operation mode. However, dilution water consumption for the purification of FOS under variable volume filtration mode was found to be less than that under constant volume filtration mode. Dey et al. [95] simulated the separation factor of $\mathrm{NF}$ membranes in separating lactic acid from fermentation broth solution, and showed that the best NF membrane can retain at least $90 \%$ of sucrose while allowing permeation of more than $70 \%$ lactic acid.

However, a single NF stage is limited by the relatively low purity and yield of sugar. Multiple stage operation, where the simplest unit is arranged in multistage membrane cascades, can improve performance. Caus et al. [96] investigated the applicability of integrated countercurrent cascades for separation of maltose and xylose. In their study, a three-stage membrane cascade with recycling of retentate was modelled on the basis of overall mass balance. To obtain maximum purity with an optimum number of membrane modules, a membrane with low rejection of xylose is preferred to maximize the rejection difference between the xylose and maltose. Patil et al. [97] investigated the effects of the stage of NF membrane cascades on the separation efficiency of OS (Fig. 3). The results show that the separation factor of the membrane for a binary mixture plays a vital role in determining the relationship between purity and yield. Compared with single stage NF, multiple stage can effectively increase product yield and purity. However, a trade-off exists between product purity and yield when the separation factor is low in a three-stage cascade. A five-stage cascade can break this trade-off even at very low separation factors. Montesdeoca et al. [62] further presented the application of a three-stage membrane cascade for purification of two commercial OS mixtures of FOS and GOS under continuous operating conditions. The established dynamic model demonstrated that purity was increased from $44.4 \%$ to $46.7 \%$ for GOS and from $84 \%$ to $94.9 \%$ for FOS, while both yields were higher than $90 \%$. The model also confirmed that trade-off phenomenon between yield and purity can be overcome by optimizing cascade configuration.

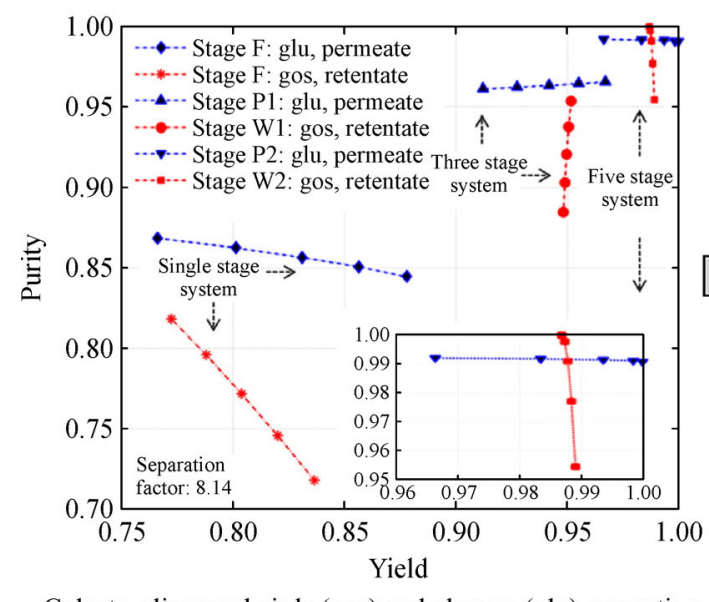

Galacto-oligosacchairde (gos) and glucose (glu) separation

(a)

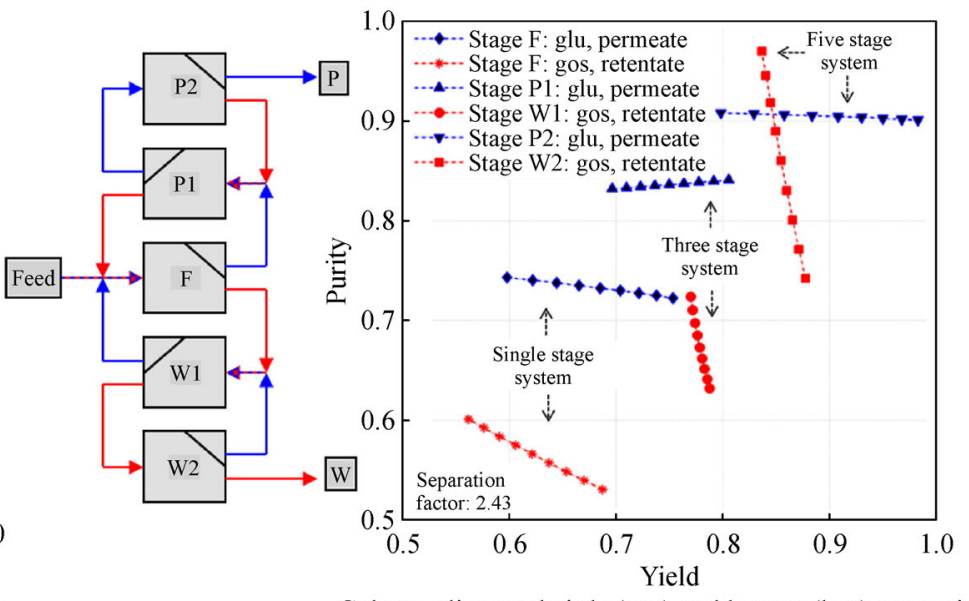

Galacto-oligosacchairde (gos) and lactose (lact) separation

(b)

Fig. 3 Impact of NF membrane stages on production yield and purity. Reprinted with permission from Ref. [97], copyright 2014 Elsevier. 


\section{Membrane fouling and control strategies}

\subsection{Membrane fouling}

Membrane fouling, termed as biological, organic, inorganic, and colloidal fouling based on the type of foulants, causes deterioration of selectivity and permeate flux, which consequently results in higher production costs [98]. Membrane fouling is therefore still a major problem in achieving efficient saccharide separation with NF systems. Foulants deposited on the NF membrane surface during purification of saccharide are classified into saccharide and non-saccharide components. The former mainly consists of polysaccharides, saccharide crystallization, etc. The latter includes high molecular weight compounds such as pigments, protein and colloidal complexes, and low molecular weight compounds such as phenolic and acetic acid [98-100]. Xue et al. [40] observed that the flux reduction of NF membranes resulted from the reversible fouling formed by residual insoluble solids during separation of lignocellulosic biomass hydrolysate. The membrane fouling was found to be primarily caused by colloidal particles and adsorbed polysaccharides (mainly pectin) during filtration of sugarcane juice [101]. According to the resistance-in-series analysis, cake fouling is the dominant mechanism. NF membranes have in particular suffered from severe fouling during separation of sucrose from by-product molasses in the saccharide industry because molasses contained various pigments and calcium ions that easily adhered to membrane surfaces [99].

The dominant membrane fouling mechanisms are formation of a cake layer and/or pore blocking, depending on the relative size of saccharide molecules and membrane pores. Pore blocking can be characterized by standard, intermediate and complete pore blocking [100-102]. Gyura et al. [103] optimized the operating conditions for separating saccharide from green syrup using NF membranes. The result showed that $49 \%$ of pigment is larger than $15 \mathrm{kDa}, 1 \%$ of this has a molecular weight between 6 and $15 \mathrm{kDa}, 18 \%$ of this is between 0.5 and $6 \mathrm{kDa}$, while the rest $(32 \%)$ is less than $0.5 \mathrm{kDa}$. Under optimum operating conditions, the pigments in the permeate decreased by $76 \%$. Balciolu et al. [104] characterized NF membrane surface by using atomic force microscopy, contact angle and Fourier transform infrared spectroscopy measurements after filtration of the sugar fermentation wastewater. They found that the fouling layer consisted of a lot of inorganic matter, in particular calcium salts and polysaccharides. The chemical structure of the membrane also significantly affects membrane fouling. Although both NF270 and Desal 5DL membranes are composite polyamide NF membranes, the NF270 membrane is a piperazine-based polyamide membrane while the Desal $5 \mathrm{DL}$ is an aromatic polyamide membrane. Compared to the aromatic polyamide membrane, the piperazine-based polyamide membrane is more hydrophilic due to a larger amount of free carboxylic acid groups $(-\mathrm{COOH})$.

Inorganic fouling causes formation of scaling, i.e., precipitation of calcium salt on the membrane surface. In addition, the polysaccharides can be crosslinked with cations ions via intermolecular interactions, and thus resulting in forming a gel layer on the membrane surface or blocking the membrane pores [105]. Biofouling is another serious problem for purification of saccharide solutions in NF membranes due to high saccharide concentrations that provides a favorable environment for biological growth, and many kinds of biologically active organisms, such as fungi and bacteria, are involved [13]. Murthy et al. [13] confirmed that the membrane surface during purification of saccharide is prone to biological fouling due to extensive and rapid fungal growth on the abundant organic sources in aqueous xylose solution. Notably, biofouling is a dynamic process involving bioattachment (adhesion and adsorption) and growth [106]. The structure of biofilm changed from a double layer to a multi-layer during biofilm growth. Development of effective strategies for inhibiting membrane fouling is of great significance for long-term stable operation of NF processes.

\subsection{Fouling control strategies}

Hydrophilic modification is an effective method for alleviating membrane fouling through physical and chemical methods [107]. Yu et al. [108] modified the polypropylene UF membrane using $\mathrm{NH}_{3}$ plasma treatment to improve its antifouling property. After $\mathrm{NH}_{3}$ plasma treatment the membrane showed higher recovery of permeate flux with simple flushing than the unmodified membrane. Pretreatment is another strategy to control membrane fouling. A disk stack centrifuge is an effective tool for removing fine suspended solids and colloidal particles (pigments and saccharide crystallization) during molasses desludging [109]. The disk stack centrifuge system rejects over $65 \%$ of the finely suspended solid material and allows a significant increase in permeate flux or cycle time. The gas-liquid two-phase flow via gas sparing was found to be effective in enhancing NF performance and, importantly, in controlling membrane fouling [110]. In a flat sheet module, the application of gas sparging could enhance limiting flux and critical flux, and cause an almost 1.5-2 fold increase in shear stress.

In addition to on-line membrane fouling control strategies, off-line membrane cleaning methods, including physical cleaning, chemical cleaning, and enzymatic cleaning, are an effective tool for maintaining the sustainability of membrane systems (Table 4). Selection of cleaning strategies depends on the characteristics of the feed solution and membrane properties. For example, Jones et al. [111] used fluid dynamic gauging to monitor 
Table 4 Membrane fouling control strategies in the sugar separation process

\begin{tabular}{|c|c|c|c|}
\hline$\overline{\text { Stock solution }}$ & Major challenge & Fouling control strategy & Ref. \\
\hline Sugarcane juice & $\begin{array}{c}\text { Formaldehyde, organic acids, chloride, and } \\
\text { antifoaming agents }\end{array}$ & Alkaline cleaning at $\mathrm{pH}=10-11$ & {$[45]$} \\
\hline Cane molasses & $\begin{array}{c}\text { Pigments and other molecules interfere with } \\
\text { crystallization }\end{array}$ & $\begin{array}{l}\text { Disk stack centrifugation removes fine suspended solids and } \\
\text { colloidal material }\end{array}$ & {$[46]$} \\
\hline Molasses wastewater & Concentration polarization resistance & Air sparging is able to mitigate membrane fouling & {$[82]$} \\
\hline Concentrated xylose solution & Glucose is conducive to rapid biological fouling & $\begin{array}{c}1 \%(\mathrm{w} / \mathrm{v}) \text { EDTA, } 2 \%(\mathrm{w} / \mathrm{v}) \text { citric acid, } 1 \%(\mathrm{w} / \mathrm{v}) \text { tri-sodium } \\
\text { phosphate aqueous solution }\end{array}$ & {$[32]$} \\
\hline
\end{tabular}

the thickness of cake layer formed during filtration of molasses solution. They found that crystals in molasses of around 1-6 $\mu \mathrm{m}$ width and 5-20 $\mu \mathrm{m}$ length resulted in severe fouling. Cleaning while the permeate line was periodically switched off was effective for the removal of cake layer in the early stage of fouling. Even so, chemical cleaning was still required to significantly recover initial permeate flux. A maximal pure water flux recovery of $89 \%$ was achieved by using a 0.25 wt- $\% \mathrm{NaOH}$ solution followed by $0.1 \mathrm{wt}-\%$ citric acid. A $0.01 \mathrm{~mol} \cdot \mathrm{L}^{-1} \mathrm{NaOH}$ cleaning solution was used to treat flux deterioration in a NF membrane and increase recovery of hydrolysates obtained from dilute acid hydrolysis of rice straw [18].

Alkaline cleaning would increase membrane surface negative charge and hydrophilicity, but somewhat destroy membrane structure. As a result, higher flux and lower retention of uncharged solutes are observed. For example, retention of glucose was decreased from $99 \%$ to $95 \%$ after alkaline cleaning [112]. In a pilot-scale NF system, Murthy et al. [13] observed that the NF membrane was especially prone to biological fouling because the feed solution contained glucose even at very low concentrations. To completely alleviate biofouling, a mixed cleaning agent, including $1 \%(\mathrm{w} / \mathrm{v})$ ethylene diamine tetraacetic acid
(EDTA), 2\% (w/v) citric acid and 1\% (w/v) tri-sodium phosphate, was used. The flux and rejection were recovered to $97 \%$ and $99 \%$ even after a 6-month running period.

\section{Development in NF technology for saccharides separation}

Production and purification of saccharides with various molecular weights require an extremely highly selective NF membrane process in order to enhance product quality and yield as well as reduce the loss of saccharides at industrial scales. Various physical and chemical techniques have been used to enhance NF membrane selectivity (Table 5).

\subsection{NF membrane modification}

Various surface modification methods including grafting (plasma treatment, etc.) or coating (layer-by-layer, LbL, etc.) techniques have been used to alter the surface properties of a polymeric or inorganic membrane. Plasma modification is a highly efficient wet-chemical surface

Table 5 Enhancement of NF technology for sugar separation ${ }^{\text {a) }}$

\begin{tabular}{|c|c|c|c|c|}
\hline Technology & Method & Sugar solution & Result & Ref. \\
\hline \multirow[t]{8}{*}{ Membrane modification } & $\begin{array}{l}\text { Virgin DK, DL, NF270 } \\
\text { D }\end{array}$ & Glucose/xylose & Limited separation & [43] \\
\hline & $\mathrm{PAN}+\mathrm{PEM}$ & Maltose/glucose & $\alpha=46$ & {$[113]$} \\
\hline & PSS/PDADMAC & $\mathrm{NaCl} /$ sucrose & $\alpha=13.3$ & {$[114]$} \\
\hline & PSS $(50 \mathrm{kDa})+$ PEM & Sucrose/glucose & $\alpha=11$ & {$[115]$} \\
\hline & & Sucrose/xylose & $\alpha=23.5$ & \\
\hline & & Glucose/xylose & $\alpha=2.1$ & \\
\hline & NF45 & $\mathrm{NaCl} /$ sucrose & $\alpha=10$ & [93] \\
\hline & {$[\mathrm{PSS} / \mathrm{PAH}]_{4}-\mathrm{PSS}$} & $\mathrm{NaCl} /$ sucrose & $\alpha=130$ & {$[116]$} \\
\hline \multirow{3}{*}{$\begin{array}{l}\text { Integrated NF membrane } \\
\text { process }\end{array}$} & Virgin NF 270 & Glucose/xylose & $\alpha=1.4$ & [52] \\
\hline & NF $270+$ enzyme & Glucose/xylose & $\alpha=34$ & \\
\hline & $\mathrm{NF}+\mathrm{ED}$ & Hydrolysis of agarose & $\begin{array}{l}62 \% \text { of LA and } 91 \% \text { of } 5-\mathrm{HMF} \text { were } \\
\text { removed by NF and then separated by } \\
\text { ED }\end{array}$ & [27] \\
\hline
\end{tabular}

a) $\alpha$-Separation factor $\alpha=\left(100-R_{\mathrm{A}}\right) /\left(100-R_{\mathrm{B}}\right)$; PSS: poly(styrenesulfonate); PAH: poly(allylamine hydrochloride); PDADMAC: poly(diallyldimethylammonium chloride); ED: electrodialysis; PEM: polyelectrolyte multilayer. 
modifying technique because of its short reaction time, high reproducibility and low environmental impact. Gulec et al. [117] modified commercial cellulose acetate membrane via low-pressure plasma polymerization for saccharide separation applications. The modified membrane showed very high retention ( $>94 \%)$ for disaccharides and rather low retention $(<73 \%)$ for monosaccharides using a modified NF membrane.

The LbL technique can control the thickness of the active layer through varying the number of polyelectrolyte layers to allow the formation of a "skin layer" with a thicknesses less than $50 \mathrm{~nm}$. The resulting membrane can achieve both high flux and rejection. Miller and Bruening [114] reported the use of polyelectrolyte PDADMAC and PSS as selective skins in a NF membrane for the separation of different saccharides. The developed PEM membrane allows the transmission of $42 \%$ glucose along with a $98 \%$ rejection of raffinose and a permeate flux of $2.4 \mathrm{~m}^{3} \cdot \mathrm{m}^{-2} \cdot \mathrm{d}^{-1}$. The PDADMAC/PSS membrane is capable of separating sucrose with a selectivity of around 10. It was found that the polyelectrolyte with a high charge density leads to a denser PEM membrane that benefits the rejection of neutral molecules, such as sucrose, glucose and glycerol. In comparison with static LbL deposition, dynamic LbL deposition allows more polyelectrolytes to enter into the pores of the substrate membrane, as shown in Fig. 4, so as to achieve high separation factors but lower flux [118]. Shi et al. [113] prepared a composite PEM (CPEM) membrane including two different polyelectrolyte pairs (such as $\left.(\mathrm{PAH} / \mathrm{PSS})_{2}+(\mathrm{CS} / \mathrm{PSS})_{3}\right)$ as an active layer to separate an OS mixture with wide molecular weight. The C-PEM membrane demonstrated moderate permeation flux and improved selectivity in comparison with single-paired PEM membranes such as (CS/PSS $)_{5}$ membrane or $(\mathrm{PAH} / \mathrm{PSS})_{5}$ membrane. Specifically, C-PEM membranes achieved a high rejection of OS (100\%) and maltose $(99.2 \%)$ but a low rejection of glucose $(63.0 \%)$, which indicated high selectivity for glucose/maltose mixture. Himstedt et al. [57] modified a commercial NF270 membrane through grafting poly(acrylic acid) on the membrane surface using a UV initiated free radical polymerization method, which enhanced the separation factor between glucose and sucrose. The hydrogen bonding interaction between the grafted polyacrylic chains and sugar molecules results in higher glucose concentration and lower sucrose concentration in the permeate at lower $\mathrm{pH}$, which explains why the rejection difference between sucrose and glucose becomes significant at low $\mathrm{pH}$.

NF membranes prepared from natural polysaccharides, such as CS and cellulose, have attracted more and more attention due to their high hydrophilicity, abundance, low cost, and environmental benignity. CS and cellulose were blended with polyethersulfone (PES) to make the NF membrane [119]. With the PES/CS and PES/cellulose blended membranes retention of saccharide for alkaline hydrolysates was $94.5 \%$ and $97.6 \%$, respectively, whereas for acidic hydrolysates the saccharide retention was about 99\% and $98 \%$ with PES/CS and PES/cellulose blended membranes, respectively. Musale and Kumar [120] prepared another CS/polyacrylonitrile composite membrane to separate saccharides. The results showed that saccharide retention relies on the degree of crosslinking of CS and that saccharide retention was in the range of $45 \%$ to $90 \%$ depending on the molecular weight of the saccharide.

The objective of membrane surface modification is generally to improve the selectivity, permeatebility, and even antifouling ability. Unlike the desalination NF membranes that suffer from severer inorganic fouling resulted from high rejection towards salts, saccharides separation NF membranes reject large saccharides and allow salts penetrate. Therefore, the cores of membrane modification for saccharides separation are the alleviation of organic and biological fouling and the enchancement of selectivity towards target saccharide. Compared to grafting technique, coating is a very simple method to implement on the large-scale fabrication. However, long-term stability and permeable impairment are still two significant challenges. To address these issues, curing the coating layer is applied to prevent the dissolution of polymer coating so as to make it stable [121]. Incorperation of nanoparticles (NPs) (i.e., CuNPs, AgNPs, GONPs etc.) into coating layer results in formation of nanochannels for improving the membrane permeability without compro-
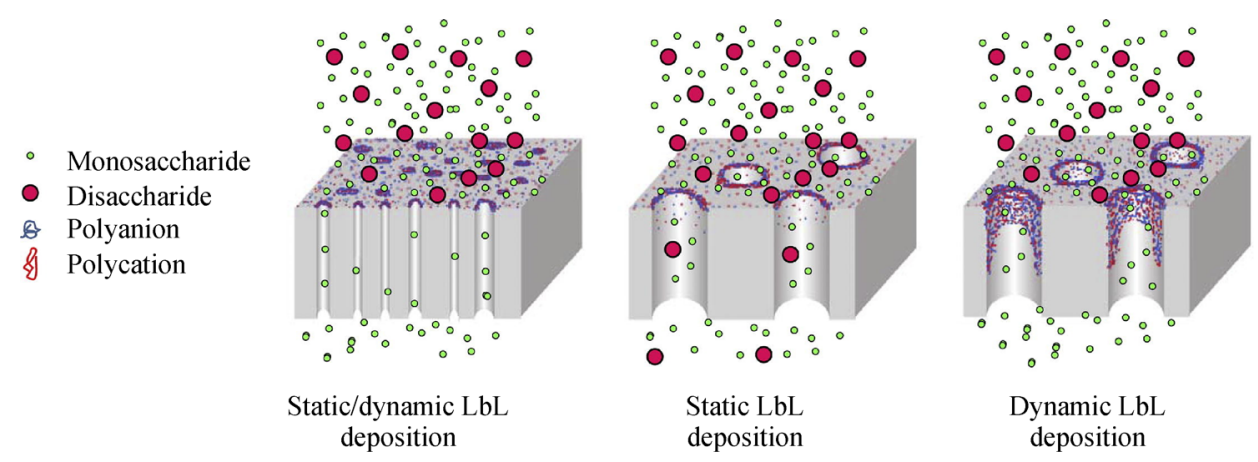

Fig. 4 Schematic diagram of different LbL deposition strategies. Reprinted with permission from Ref. [119], copyright 2013 Elsevier. 
mising the membrane selectivity [122]. The future direction of membrane modification technique will be focused on development of new methods that can be implemented in large-scale membrane fabrication through considering the stability and operating costs.

\subsection{Integrated NF processes}

Integration of NF with other advanced processes can maximize the efficiency of saccharide recovery due to technique complementation. Enzymatic treatment has been widely used in the purification of saccharide using the biomass hydrolysis reaction. Morthensen et al. [52] demonstrated an enzymatic process for converting glucose to gluconic acid followed by separation of xylose from the gluconic acid using a NF270 membrane. Under the best conditions (total feed concentration of $0.15 \mathrm{~mol} \cdot \mathrm{L}^{-1}$, molar ratio of xylose to gluconic acid of 9:1, operating pressure of 4 bar, and $\mathrm{pH} 9.5$ ), a xylose separation factor of 34 and a flux of $18.7 \mathrm{~L} \cdot \mathrm{m}^{-2} \cdot \mathrm{h}$ could be achieved, whereas the initial separation factor between xylose and glucose without enzymatic pretreatment was only 1.4 for the same process. Similarly, Machado et al. [49] proposed a combination of enzymatic treatment with a NF membrane process to recover biologically active OS from defatted milk. The experimental results showed that enzymatic hydrolysis of lactose can significantly enhance the selectivity and efficiency of the NF membrane. Under optimum operation conditions, $6.7 \mathrm{~g}$ of OS could be produced from one litre of defatted human milk after four NF cycles. However, the enzymatic process faces challenges of low efficiency and high cost due to inactivation of the enzymes. To address these issues, the membranes can be used as supports for enzyme immobilization, which enhances performance and economic viability and, importantly, facilitates simultaneous reaction-purification of the products as shown in Fig. 5 [123]. The enzyme immobilized polymeric membrane has been used to produce galactooligosaccharides from lactose solution [124]. The regenerated cellulose membrane surface has a larger amount of immobilized enzyme compared to the PES membrane, which thus achieves a higher recovery of galacto-oligosaccharide from lactose solution.

Ionic liquids for biomass pretreatment has been proved to effectively convert cellulose to glucose because they can dissolve lignocellulosic biomass efficiently while simultaneously decreasing the crystallinity of cellulose. Abels et al. [125] developed an ionic liquid based hybrid process which included ionic liquid pretreatment, enzymatic hydrolysis and a NF process. The NF membrane was applied to purify the glucose from impurities and recover the ionic liquid back to the pretreatment reactor. Although the whole process is technically feasible, the high cost of the ionic liquid accounts for $33 \%$ of the total costs, which limits large scale application of this approach in practice.

ED is an electro-driven membrane-based technology that can effectively separate charged molecules like acid from uncharged solutes like sugar. Kim et al. [27] separated 5-HMF, LA and galactose in an acidic hydrolysate of agarose by using a hybrid NF-ED process. The NF membrane was applied first to remove LA and 5-HMF from galactose solution, and at this stage more than $62 \%$ of LA and $91 \%$ of 5-HMF were removed from agarose hydrolysate. Subsequently, LA and 5-HMF could be effectively separated using the ED process.

\section{Outlooks}

There is growing interest in the extraction and purification of saccharides from natural biomass rather than synthetic saccharide production. Application of NF for extraction of high value saccharides in the field of functional foods and biofuels has increased fast in the last decade. Although NF is a mature technology, its applications still face some challenges, including high cost, membrane fouling and long-term stability at industrial scale. The following improvements to NF technology for saccharide recovery may be undertaken to achieve the goals of high efficiency, low energy, and low fouling tendency.

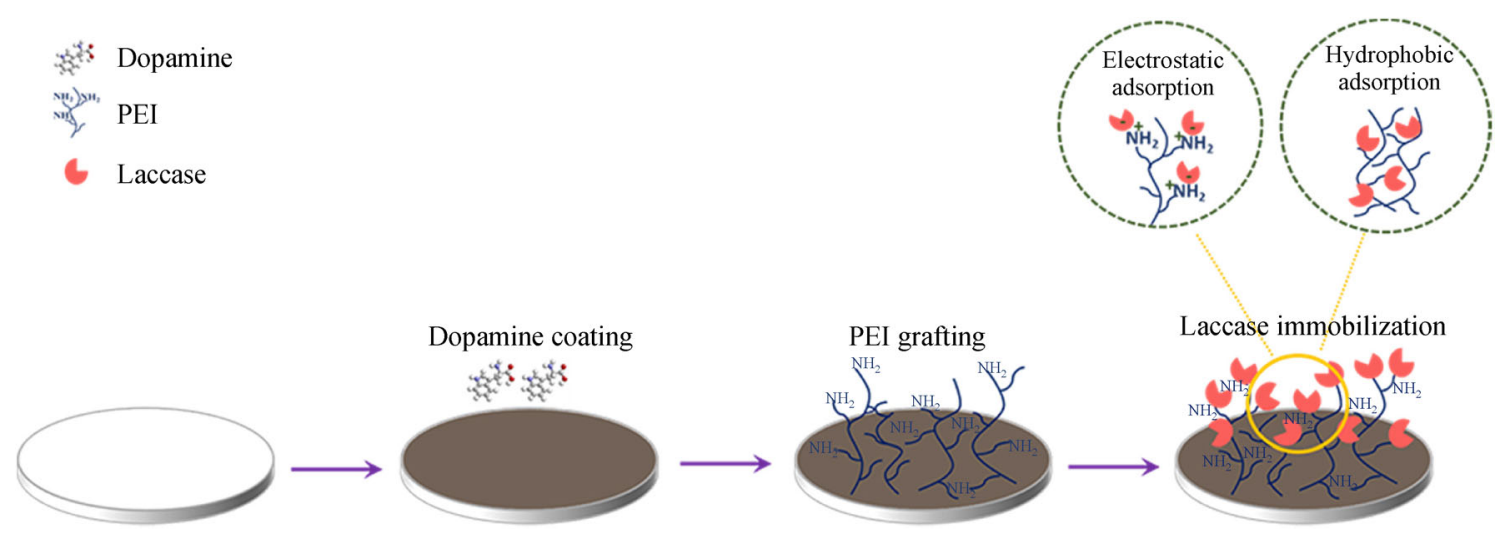

Fig. 5 Schematic diagram of a biocatalytic membrane prepared via enzyme immobilization. Reprinted with permission from Ref. [123], copyright 2018 Elsevier. 
Selection of an appropriate NF membrane is critical for the specific saccharide separation. Membrane selection generally depends on the interactions between the solute and membrane. For example, besides the membrane pore size, the charge density and characteristics of the membrane surface are also key factors in the separation of charged saccharides such as POS. However, most commercially available NF membranes are polyamidebased composite membranes. The skin layers are normally negatively charged at $\mathrm{pH}>4$ and their surface Zetapotential can only be adjusted by changes of $\mathrm{pH}$. To achieve better separation performance and selectivity, membrane modification techniques such as LbL and plasma treatment can be performed to produce a more controllable charged surface to enhance the Donnan effect.

Another important issue is to decrease irreversible fouling on the NF membranes because fouling formation and chemical cleaning would reduce production efficiency and shorten the lifespan of the membranes. Permeate flux and selectivity may be enhanced and membrane fouling reduced by modifying the NF membrane surface using polymerization/coating with a hydrophilic polymers (e.g., polyvinyl alcohol, polyethylene glycol, etc.) or incorporation of functional NPs (e.g., graphene oxide, metalorganic frameworks, etc.) to increase hydrophilicity and reduce membrane surface roughness. The reduction or tuning of membrane surface charge is preferred in order to decrease the ionic bridge between membrane and charged saccharide. In practical large-scale membrane processes, the membrane module configuration and operating conditions have great significance for filtration sustainability. To predict the separation performance during steady-state filtration process, establishment of a reliable model is highly encouraged based on different principles such as convection-diffusion model, osmotic pressure model, thermodynamics and hydrodynamics equations, etc. In addition to theoretical calculations, some online and noninvasive monitoring techniques (such as ultrasonics, electrical impedance spectroscopy etc.) can be used to evaluate the fouling potential in an early stage so as to timely clean membrane.

Each technology has its own merits and limitations. To maximize the overall separation efficiency of saccharide, combining of NF process with other separation technologies are highly encouraged. For example, the hybrid UF$\mathrm{NF}$ membrane process is well-recognized as an effective method for recovering saccharide because UF can greatly mitigate fouling formation of NF. However, since the NF membrane is limited to rejecting monovalent ions, an additional process (such as ion exchange and electrodialysis) should be introduced to remove the residual inorganic ions. Finally, high-purity concentrated saccharide can be obtained by using a vacuum evaporation process, such as membrane distillation, for removal of remaining water. Reasonable capital cost and energy consumption are the keys to establishing a sustainable membrane-integrated separation process.

In summary, improvements of NF membrane would be performed considering the operating cost and system stability with an ultimate goal of accomplishment of longterm and full-scale applications.

\section{Conclusions}

Notwithstanding the fact that much success has been achieved in the saccharides extraction from biomass using NF membrane. This work presented an overview and commentary of published studies on advanteges and challenges of NF processes for separation and purification of saccharides. This study gives us a comprehensive understanding of the saccharide transport mechanisms and of the interaction between significant operating parameters, which provides a guideline of the selection for NF membrane to purify saccharides from different feedstocks. However, wider application of NF technique requires overcoming the challenges of lowering the overall cost, alleviating membrane scaling difficulties, and increasing long-term stability. To ensure sustainable separation efficiency, future research may be invested in membrane surface modification and module optimization for achieving low fouling tendency and high permeselectivity. The innovative hybrid system combining NF process with different separation processes is a promising sustainable technique. However, the hybridised NF-based process in saccharides extraction should be performed considering the system stability and operating cost. In sum, the present selective NF membrane process could serve as a promising and highly efficient separation platform for removal and separation of saccharides from biomass.

Acknowledgements Dr. X. Li thanks the European Union's Horizon 2020 Research and Innovation Program for funding under Marie SklodowskaCurie Grant Agreement No. 713683 (COFUNDfellowsDTU).

\section{References}

1. Moure A, Gullón P, Domínguez H, Parajó J C. Advances in the manufacture, purification and applications of xylo-oligosaccharides as food additives and nutraceuticals. Process Biochemistry, 2016, 41(9): 1913-1923

2. Peters D. Carbohydrates for fermentation. Biotechnology Journal, 2006, 1(7-8): 806-814

3. Isikgor $\mathrm{F} \mathrm{H}$, Remzi Becer C. Lignocellulosic biomass: a sustainable platform for production of bio-based chemicals and polymers. Polymer Chemistry, 2015, 6(25): 4497-4559

4. Kamm B, Kamm M. Biorefinery-systems. Chemical and Biochemical Engineering Quarterly, 2004, 18: 1-7

5. Roca C, Alves V D, Freitas F, Reis M A M. Exopolysaccharides enriched in rare sugars: bacterial sources, production, and applications. Frontiers in Microbiology, 2015, 6: 1-7 
6. Beerens K, Desmet T, Soetaert W. Enzymes for the biocatalytic production of rare sugars. Journal of Industrial Microbiology \& Biotechnology, 2012, 39(6): 823-834

7. Carbohydrates in Human Nutrition: Report of a Joint FAO/WHO Expert Consultation. Rome, 1997

8. Bandini S, Nataloni L. Nanofiltration for dextrose recovery from crystallization mother liquors: a feasibility study. Separation and Purification Technology, 2015, 139: 53-62

9. Salmi T, Holmbom B, Willf S, Murzin D Y. Synthesis of sugars by hydrolysis of hemicelluloses: a review. Chemical Reviews, 2011, 111(9): 5638-5666

10. Pinelo M, Jonsson G, Meyer A S. Membrane technology for purification of enzymatically produced oligosaccharides: molecular and operational features affecting performance. Separation and Purification Technology, 2009, 70(1): 1-11

11. Pruksasri S, Nguyen T H, Haltrich D, Novalin S. Fractionation of a galacto-oligosaccharides solution at low and high temperature using nanofiltration. Separation and Purification Technology, 2015, 151: $124-130$

12. Sasaki K, Sasaki D, Sakihama Y, Teramura H, Yamada R, Hasunuma T, Ogino C, Kondo A. Ethanol fermentation by xyloseassimilating Saccharomyces cerevisiae using sugars in a rice straw liquid hydrolysate concentrated by nanofiltration. Bioresource Technology, 2013, 147: 84-88

13. Murthy G S, Sridhar S, Shyam Sunder M, Shankaraiah B, Ramakrishna M. Concentration of xylose reaction liquor by nanofiltration for the production of xylitol sugar alcohol. Separation and Purification Technology, 2005, 44(3): 221-228

14. Fornefett I, Rabet D, Buttersack C, Buchholz K. Adsorption of sucrose on zeolites. Green Chemistry, 2016, 18(11): 3378-3388

15. Sen D, Gosling A, Stevens G W, Bhattacharya P K, Barber A R, Kentish S E, Bhattacharjee C, Gras S L. Galactosyl oligosaccharide purification by ethanol precipitation. Food Chemistry, 2011, 128 (3): 773-777

16. Saari P, Heikkila H, Hurme M. Adsorption equilibria of arabinose, fructose, galactose, glucose, mannose, rhamnose, sucrose, and xylose on ion-exchange resins. Journal of Chemical \& Engineering Data, 2010, 55(9): 3462-3467

17. Bi W, Zhou J, Row K H. Separation of xylose and glucose on different silica-confined ionic liquid stationary phases. Analytica Chimica Acta, 2010, 667(2): 162-168

18. Weng Y H, Wei H J, Tsai T Y, Lin T H, Wei T Y, Guo G L, Huang C P. Separation of furans and carboxylic acids from sugars in dilute acid rice straw hydrolyzates by nanofiltration. Bioresource Technology, 2010, 101(13): 4889-4894

19. Blanc C L, Lemaire J, Duval F, Théoleyre M A, Pareau D. Purification of pentoses from hemicellulosic hydrolysates without neutralization for sulfuric acid recovery. Separation and Purification Technology, 2017, 174: 513-519

20. Wei P, Cheng L H, Zhang L, Xu X H, Chen H L, Gao C J. A review of membrane technology for bioethanol production. Renewable \& Sustainable Energy Reviews, 2014, 30: 388-400

21. Goulas A K, Kapasakalidis P G, Sinclair H R, Rastall R A, Grandison A S. Purification of oligosaccharides by nanofiltration. Journal of Membrane Science, 2002, 209(1): 321-335

22. Moulik S, Vadthya P, Kalipatnapu Y R, Chenna S, Sundergopal S.
Production of fructose sugar from aqueous solutions: nanofiltration performance and hydrodynamic analysis. Journal of Cleaner Production, 2015, 92: 44-53

23. Cheng H, Wang H, Lv J, Jiang M, Lin S, Deng Z. A novel method to prepare L-arabinose from xylose mother liquor by yeastmediated biopurification. Microbial Cell Factories, 2011, 10(1): 111

24. Kobayashi H, Fukuoka A. Synthesis and utilisation of sugar compounds derived from lignocellulosic biomass. Green Chemistry, 2013, 15(7): 1740-1763

25. Aguedo M, Vanderghem C, Goffin D, Richel A, Paquot M. Fast and high yield recovery of arabinose from destarched wheat bran. Industrial Crops and Products, 2013, 43: 318-325

26. Granström T B, Takata G, Tokuda M, Izumori K. Izumoring: a novel and complete strategy for bioproduction of rare sugars. Journal of Bioscience and Bioengineering, 2004, 97(2): 89-94

27. Kim J H, Na J G, Yang J W, Chang Y K. Separation of galactose, 5hydroxymethylfurfural and levulinic acid in acid hydrolysate of agarose by nanofiltration and electrodialysis. Bioresource Technology, 2013, 140: 64-72

28. Kamm B, Patrick R, Michael K. Biorefineries-Industrial Processes and Products. Weinheim: Wiley-VCH, 2006, 1-949

29. Kuhn R C, Maugeri Filho F, Silva V, Palacio L, Hernández A, Prádanos $\mathrm{P}$. Mass transfer and transport during purification of fructooligosaccharides by nanofiltration. Journal of Membrane Science, 2010, 365(1-2): 356-365

30. Mussatto S I, Mancilha I M. Non-digestible oligosaccharides: a review. Carbohydrate Polymers, 2007, 68(3): 587-597

31. Zhao H, Hua X, Yang R, Zhao L, Zhao W, Zhang Z. Diafiltration process on xylo-oligosaccharides syrup using nanofiltration and its modelling. International Journal of Food Science \& Technology, 2012, 47(1): 32-39

32. Kumar A S, Mody K, Jha B. Bacterial exopolysaccharides - a perception. Journal of Basic Microbiology, 2007, 47(2): 103-117

33. Bachelder E M, Beaudette T T, Broaders K E, Dashe J, Fréchet J M J. Acetal-derivatized dextran: an acid-responsive biodegradable material for therapeutic applications. Journal of the American Chemical Society, 2008, 130(32): 10494-10495

34. Mousavi S M, Moghadam M T. Separation of sugar from molasses by ultrafiltration and nanofiltration. World Applied Sciences Journal, 2009, 7: 632-636

35. Christakopoulos P, Katapodis P, Kalogeris E, Kekos D, Macris B J, Stamatis H, Skaltsa H. Antimicrobial activity of acidic xylooligosaccharides produced by family 10 and 11 endoxylanases. International Journal of Biological Macromolecules, 2003, 31(45): $171-175$

36. Swennen K, Courtin C M, Van Der Bruggen B, Vandecasteele C, Delcour J A. Ultrafiltration and ethanol precipitation for isolation of arabinoxylooligosaccharides with different structures. Carbohydrate Polymers, 2005, 62(3): 283-292

37. Vegas R, Alonso L, Domínguez H, Parajó J C. Processing of rice husk autohydrolysis liquors for obtaining food ingredients. Journal of Agricultural and Food Chemistry, 2004, 52(24): 7311-7317

38. Nobre C, Teixeira J A, Rodrigues L R. New trends and technological challenges in the industrial production and purification of fructo-oligosaccharides. Critical Reviews in Food Science 
and Nutrition, 2013, 55(10): 1444-1455

39. Meinita M D N, Hong Y K, Jeong G T. Detoxification of acidic catalyzed hydrolysate of Kappaphycus alvarezii (cottonii). Bioprocess and Biosystems Engineering, 2012, 35(1-2): 93-98

40. Xue J L, Zhao S, Liang R M, Yin X, Jiang S X, Su L H, Yang Q, Duan C J, Liu J L, Feng J X. A biotechnological process efficiently co-produces two high value-added products, glucose and xylooligosaccharides, from sugarcane bagasse. Bioresource Technology, 2016, 204: 130-138

41. Yapo B M, Robert C, Etienne I, Wathelet B, Paquot M. Effect of extraction conditions on the yield, purity and surface properties of sugar beet pulp pectin extracts. Food Chemistry, 2007, 100(4): 1356-1364

42. Sharma M, Patel S N, Lata K, Singh U, Krishania M, Sangwan R S, Singh S P. A novel approach of integrated bioprocessing of cane molasses for production of prebiotic and functional bioproducts. Bioresource Technology, 2016, 219: 311-318

43. Sjöman E, Mänttäri M, Nyström M, Koivikko H, Heikkilä H. Separation of xylose from glucose by nanofiltration from concentrated monosaccharide solutions. Journal of Membrane Science, 2007, 292(1-2): 106-115

44. Alam M N H Z, Pinelo M, Samanta K, Jonsson G, Meyer A, Gernaey K V. A continuous membrane microbioreactor system for development of integrated pectin modification and separation processes. Chemical Engineering Journal, 2011, 167(2-3): 418426

45. Lyu H, Fang Y, Ren S, Chen K, Luo G, Zhang S, Chen J. Monophenols separation from monosaccharides and acids by twostage nanofiltration and reverse osmosis in hydrothermal liquefaction hydrolysates. Journal of Membrane Science, 2016, 504: 141152

46. Luo J, Zeuner B, Morthensen T, Meyer A S, Pinelo M. Separation of phenolic acids from monosaccharides by low-pressure nanofiltration integrated with laccase pre-treatments. Journal of Membrane Science, 2015, 482: 83-91

47. Kamada T, Nakajima M, Nabetani H, Saglam N, Iwamoto S. Availability of membrane technology for purifying and concentrating oligosaccharides. European Food Research and Technology, 2002, 214(5): 435-440

48. Sanz M L, Polemis N, Morales V, Corzo N, Drakoularakou A, Gibson G R, Rastall R A. In vitro investigation into the potential prebiotic activity of honey oligosaccharides. Journal of Agricultural and Food Chemistry, 2005, 53(8): 2914-2921

49. Machado M T C, Trevisan S, Pimentel-Souza J D R, Pastore G M, Hubinger M D. Clarification and concentration of oligosaccharides from artichoke extract by a sequential process with microfiltration and nanofiltration membranes. Journal of Food Engineering, 2016, 180: $120-128$

50. Camelini C M, Rezzadori K, Benedetti S, Proner M C, Fogaça L, Azambuja A A, Giachini A J, Rossi M J, Petrus J C C. Nanofiltration of polysaccharides from Agaricus subrufescens. Applied Microbiology and Biotechnology, 2013, 97(23): 999310002

51. Giacobbo A, Bernardes A M, De Pinho M N. Nanofiltration for the recovery of low molecular weight polysaccharides and polyphenols from winery effluents. Separation Science and Technology,
2013, 48(17): 2524-2530

52. Morthensen S T, Luo J, Meyer A S, Jørgensen H, Pinelo M. High performance separation of xylose and glucose by enzyme assisted nanofiltration. Journal of Membrane Science, 2015, 492: 107-115

53. Qi B, Luo J, Chen X, Hang X, Wan Y. Separation of furfural from monosaccharides by nanofiltration. Bioresource Technology, 2011, 102(14): 7111-7118

54. Li W, Li J, Chen T, Chen C. Study on nanofiltration for purifying fructo-oligosaccharides: I. Operation modes. Journal of Membrane Science, 2004, 245(1-2): 123-129

55. Himstedt H H, Du H, Marshall K M, Wickramasinghe S R, Qian X. $\mathrm{pH}$ responsive nanofiltration membranes for sugar separations. Industrial \& Engineering Chemistry Research, 2013, 52(26): 9259-9269

56. Luo J, Guo S, Wu Y, Wan Y. Separation of sucrose and reducing sugar in cane molasses by nanofiltration. Food and Bioprocess Technology, 2018, 11(5): 913-925

57. Faneer K A, Rohani R, Mohammad A W, Ba Abbad M M. Evaluation of the operating parameters for the separation of xylitol from a mixed sugar solution by using a polyethersulfone nanofiltration membrane. Korean Journal of Chemical Engineering, 2017, 34(11): 2944-2957

58. Akin $\mathrm{O}$, Temelli F, Köseoğlu S. Membrane applications in functional foods and nutraceuticals. Critical Reviews in Food Science and Nutrition, 2012, 52(4): 347-371

59. Grandison A S, Goulas A K, Rastall R A. The use of dead-end and cross-flow nanofiltration to purify prebiotic oligosaccharides from reaction mixtures. Songklanakarin Journal of Science and Technology, 2002, 24: 915-928

60. Singh R D, Nadar C G, Muir J, Arora A. Green and clean process to obtain low degree of polymerisation xylooligosaccharides from almond shell. Journal of Cleaner Production, 2019, 241: 118237

61. Oliveira D L, Wilbey R A, Grandison A S, Duarte L C, Roseiro L B. Separation of oligosaccharides from caprine milk whey prior to prebiotic evaluation. International Dairy Journal, 2012, 24(2): 102-106

62. Aguirre Montesdeoca V, van Der Padt A, Boom R M, Janssen A E M. Modelling of membrane cascades for the purification of oligosaccharides. Journal of Membrane Science, 2016, 520: 712722

63. Sen D, Sarkar A, Das S, Chowdhury R, Bhattacharjee C. Batch hydrolysis and rotating disk membrane bioreactor for the production of galacto-oligosaccharides: a comparative study. Industrial \& Engineering Chemistry Research, 2012, 51(32): 10671-10681

64. Iwasaki K, Matsubara Y. Purification of pectate oligosaccharides showing root-growth promoting activity in lettuce using ultrafiltration and nanofiltration membranes. Journal of Bioscience and Bioengineering, 2000, 89(5): 495-497

65. Sukhbaatar B, Hassan E B, Kim M, Steele P, Ingram L. Optimization of hot-compressed water pretreatment of bagasse and characterization of extracted hemicelluloses. Carbohydrate Polymers, 2014, 101: 196-202

66. Karabelas A J, Karanasiou A, Sioutopoulos D C. Experimental study on the effect of polysaccharides on incipient membrane scaling during desalination. Desalination, 2017, 416: 106-121 
67. Fonseca A C, Summers R S, Greenberg A R, Hernandez M T. Extra-cellular polysaccharides, soluble microbial products, and natural organic matter impact on nanofiltration membranes flux decline. Environmental Science \& Technology, 2007, 41(7): 24912497

68. Broeckmann A, Wintgens T, Schäfer A I. Removal and fouling mechanisms in nanofiltration of polysaccharide solutions. Desalination, 2005, 178(1-3): 149-159

69. Zhang Y, Wang Y, Cao X, Xue J, Zhang Q, Tian J, Li X, Qiu X, Pan B, Gu A Z, Zheng X. Effect of carboxyl and hydroxyl groups on adsorptive polysaccharide fouling: a comparative study based on PVDF and graphene oxide (GO) modified PVDF surfaces. Journal of Membrane Science, 2020, 595: 117514

70. Luo J, Hang X, Zhai W, Qi B, Song W, Chen X, Wan Y. Refining sugar cane juice by an integrated membrane process: filtration behavior of polymeric membrane at high temperature. Journal of Membrane Science, 2016, 509: 105-115

71. Guo S, Luo J, Wu Y, Qi B, Chen X, Wan Y. Decoloration of sugarcane molasses by tight ultrafiltration: filtration behavior and fouling control. Separation and Purification Technology, 2018, 204: 66-74

72. Guo S, Luo J, Yang Q, Qiang X, Feng S, Wan Y. Decoloration of molasses by ultrafiltration and nanofiltration: unraveling the mechanisms of high sucrose retention. Food and Bioprocess Technology, 2019, 12(1): 39-53

73. Luo J, Guo S, Qiang X, Hang X, Chen X, Wan Y. Sustainable utilization of cane molasses by an integrated separation process: interplay between adsorption and nanofiltration. Separation and Purification Technology, 2019, 219: 16-24

74. Qiang X, Luo J, Guo S, Cao W, Hang X, Liu J, Wan Y. A novel process for molasses utilization by membrane filtration and resin adsorption. Journal of Cleaner Production, 2019, 207: 432-443

75. Gautam A, Menkhaus T J. Performance evaluation and fouling analysis for reverse osmosis and nanofiltration membranes during processing of lignocellulosic biomass hydrolysate. Journal of Membrane Science, 2014, 451: 252-265

76. Weng Y H, Wei H J, Tsai T Y, Chen W H, Wei T Y, Hwang W S, Wang C P, Huang C P. Separation of acetic acid from xylose by nanofiltration. Separation and Purification Technology, 2009, 67 (1): 95-102

77. Love D J, Muzzell D J. Minimising sucrose loss in final molasses: the three laws of molasses loss. International Sugar Journal, 2009, 111(1332): 730-737

78. Liu M, Zhu H, Dong B, Zheng Y, Yu S, Gao C. Submerged nanofiltration of biologically treated molasses fermentation wastewater for the removal of melanoidins. Chemical Engineering Journal, 2013, 223: 388-394

79. Peshev D, Livingston A G. OSN Designer, a tool for predicting organic solvent nanofiltration technology performance using Aspen One, MATLAB and CAPE OPEN. Chemical Engineering Science, 2013, 104: 975-987

80. Shi B, Marchetti P, Peshev D, Zhang S, Livingston A G. Performance of spiral-wound membrane modules in organic solvent nanofiltration-fluid dynamics and mass transfer characteristics. Journal of Membrane Science, 2015, 494: 8-24

81. Bargeman G, Vollenbroek J M, Straatsma J, Schroën C G P H,
Boom R M. Nanofiltration of multi-component feeds. Interactions between neutral and charged components and their effect on retention. Journal of Membrane Science, 2005, 247(1-2): 11-20

82. Otero J A, Mazarrasa O, Villasante J, Silva V, Prádanos P, Calvo J I, Hernández A. Three independent ways to obtain information on pore size distributions of nanofiltration membranes. Journal of Membrane Science, 2008, 309(1-2): 17-27

83. Hilal N, Darwish N A, Mohammad A W, Arabi M A. A comprehensive review of nanofiltration membranes: treatment, pretreatment, modelling, and atomic force microscopy. Desalination, 2004, 170(3): 281-308

84. Zhang Y, Zhang L, Hou L, Kuang S B, Yu A B. Modeling of the variations of permeate flux, concentration polarization, and solute rejection in nanofiltration system. AIChE Journal. American Institute of Chemical Engineers, 2019, 65(3): 1076-1087

85. Li W, Li J, Chen T, Zhao Z, Chen C. Study on nanofiltration for purifying fructo-oligosaccharides: II. Extended pore model. Journal of Membrane Science, 2005, 258(1-2): 8-15

86. Agenson K O, Oh J I, Urase T. Retention of a wide variety of organic pollutants by different nanofiltration/reverse osmosis membranes: controlling parameters of process. Journal of Membrane Science, 2003, 225(1-2): 91-103

87. Kiso Y, Muroshige K, Oguchi T, Yamada T, Hhirose M, Ohara T, Shintani T. Effect of molecular shape on rejection of uncharged organic compounds by nanofiltration membranes and on calculated pore radii. Journal of Membrane Science, 2010, 358(12): 101-113

88. Kiso Y, Kon T, Kitao T, Nishimura K. Rejection properties of alkyl phthalates with nanofiltration membranes. Journal of Membrane Science, 2001, 182(1-2): 205-214

89. Neuhaus W, Novalin S, Klimacek M, Splechtna B, Petzelbauer I, Szivak A, Kulbe K D. Optimization of an innovative hollow-fiber process to produce lactose-reduced skim milk. Applied Biochemistry and Biotechnology, 2006, 134(1): 1-14

90. Bandini S, Morelli V. Effect of temperature, $\mathrm{pH}$ and composition on nanofiltration of mono/disaccharides: experiments and modeling assessment. Journal of Membrane Science, 2017, 533: 57-74

91. Boy V, Roux de Balmann H, Galier S. Relationship between volumetric properties and mass transfer through NF membrane for saccharide/electrolyte systems. Journal of Membrane Science, 2012, 390-391: 254-262

92. Lipnizki F, Boelsmand J, Madsen R F. Concepts of industrial-scale diafiltration systems. Desalination, 2002, 144(1-3): 179-184

93. Wang X L, Zhang C, Ouyang P. The possibility of separating saccharides from a $\mathrm{NaCl}$ solution by using nanofiltration in diafiltration mode. Journal of Membrane Science, 2002, 204(1-2): 271-281

94. Ortiz Cerda I E, Bonnin J, Bostyn S, Ruiz Cabrera M A, Moscosa Santillán M. Experimental and CFD modeling study of inulin-type fructan purification from a model solution by diafiltration on a pilot-scale unit. Separation Science and Technology, 2014, 49(8): $1125-1134$

95. Dey P, Linnanen L, Pal P. Separation of lactic acid from fermentation broth by cross flow nanofiltration: membrane characterization and transport modelling. Desalination, 2012, 288: $47-57$ 
96. Caus A, Braeken L, Boussu K, Van der Bruggen B. The use of integrated countercurrent nanofiltration cascades for advanced separations. Journal of Chemical Technology and Biotechnology (Oxford, Oxfordshire), 2009, 84(3): 391-398

97. Patil N V, Janssen A E M, Boom R M. The potential impact of membrane cascading on downstream processing of oligosaccharides. Chemical Engineering Science, 2014, 106: 86-98

98. Choudhury R R, Gohil J M, Mohanty S, Nayak S K. Antifouling, fouling release and antimicrobial materials for surface modification of reverse osmosis and nanofiltration membranes. Journal of Materials Chemistry. A, Materials for Energy and Sustainability, 2018, 6(2): 313-333

99. Tang C Y, Chong T H, Fane A G. Colloidal interactions and fouling of $\mathrm{NF}$ and RO membranes: a review. Advances in Colloid and Interface Science, 2011, 164(1-2): 126-143

100. Mondal S, De S. A fouling model for steady state crossflow membrane filtration considering sequential intermediate pore blocking and cake formation. Separation and Purification Technology, 2010, 75(2): 222-228

101. Saha N K, Balakrishnan M, Ulbricht M. Sugarcane juice ultrafiltration: FTIR and SEM analysis of polysaccharide fouling. Journal of Membrane Science, 2007, 306(1-2): 287-297

102. Almandoz C, Pagliero C, Ochoa A, Marchese J. Corn syrup clarification by microfiltration with ceramic membranes. Journal of Membrane Science, 2010, 363(1-2): 87-95

103. Gyura J, Šereš Z, Eszterle M. Influence of operating parameters on separation of green syrup colored matter from sugar beet by ultraand nanofiltration. Journal of Food Engineering, 2005, 66(1): 8996

104. Balciolu G, Gönder Z B. Recovery of baker's yeast wastewater with membrane processes for agricultural irrigation purpose: fouling characterization. Chemical Engineering Journal, 2014, 255: 630-640

105. Meng S, Meng X, Fan W, Liang D, Wang L, Zhang W, Liu Y. The role of transparent exopolymer particles (TEP) in membrane fouling: a critical review. Water Research, 2020, 181: 115930

106. Fortunato L, Jeong S, Leiknes T O. Time-resolved monitoring of biofouling development on a flat sheet membrane using optical coherence tomography. Scientific Reports, 2017, 7(1): 15

107. Mustafa G, Wyns K, Buekenhoudt A, Meynen V. New insights into the fouling mechanism of dissolved organic matter applying nanofiltration membranes with a variety of surface chemistries. Water Research, 2016, 93: 195-204

108. Yu H Y, Hu M X, Xu Z K, Wang J L, Wang S Y. Surface modification of polypropylene microporous membranes to improve their antifouling property in MBR: $\mathrm{NH}_{3}$ plasma treatment. Separation and Purification Technology, 2005, 45(1): 8-15

109. Khammar M, Xu Y M. Continuous liquid extraction from saturated granular materials. Chemical Engineering Science, 2017, 173: 390-401

110. Nath K, Patel T M. Mitigation of flux decline in the cross-flow nanofiltration of molasses wastewater under the effect of gas sparging. Separation Science and Technology, 2014, 49(10): 14791489

111. Jones S A, Chew Y M J, Wilson D I, Bird M R. Fluid dynamic gauging of microfiltration membranes fouled with sugar beet molasses. Journal of Food Engineering, 2012, 108(1): 22-29

112. Mänttäri M, Pihlajamäki A, Kaipainen E, Nyström M. Effect of temperature and membrane pre-treatment by pressure on the filtration properties of nanofiltration membranes. Desalination, 2002, 145(1-3): 81-86

113. Shi J, Zhang W, Su Y, Jiang Z. Composite polyelectrolyte multilayer membranes for oligosaccharides nanofiltration separation. Carbohydrate Polymers, 2013, 94(1): 106-113

114. Miller M D, Bruening M L. Controlling the nanofiltration properties of multilayer polyelectrolyte membranes through variation of film composition. Langmuir, 2004, 20(26): 1154511551

115. Malmali M, Wickramasinghe S R, Tang J, Cong H. Sugar fractionation using surface-modified nanofiltration membranes. Separation and Purification Technology, 2016, 166: 187-195

116. Hong S U, Miller M D, Bruening M L. Removal of dyes, sugars, and amino acids from $\mathrm{NaCl}$ solutions using multilayer polyelectrolyte nanofiltration membranes. Industrial \& Engineering Chemistry Research, 2006, 45(18): 6284-6288

117. Gulec H A, Topacli A, Topacli C, Albayrak N, Mutlu M. Modification of cellulose acetate membrane via low-pressure plasma polymerization for sugar separation applications: Part I. Membrane development and characterization. Journal of Membrane Science, 2010, 350(1-2): 310-321

118. Malmali M, Wickramasinghe S R, Tang J, Cong H. Sugar fractionation using surface-modified nanofiltration membranes. Separation and Purification Technology, 2016, 166: 187-195

119. Lakra R, Saranya R, Lukka Thuyavan Y, Sugashini S, Begum K M M S, Arthanareeswaran G. Separation of acetic acid and reducing sugars from biomass derived hydrosylate using biopolymer blend polyethersulfone membrane. Separation and Purification Technology, 2013, 118: 853-861

120. Musale D A, Kumar A. Effects of surface crosslinking on sieving characteristics of chitosan/poly(acrylonitrile) composite nanofiltration membranes. Separation and Purification Technology, 2000, 21 (1-2): $27-38$

121. Suwaileh W, Johnson D, Khodabakhshi S, Hilal N. Development of forward osmosis membranes modified by cross-linked layer by layer assembly for brackish water desalination. Journal of Membrane Science, 2019, 583: 267-277

122. Yang Z, Guo H, Yao Z K, Mei Y, Tang C Y. Hydrophilic silver nanoparticles induce selective nanochannels in thin film nanocomposite polyamide membranes. Environmental Science \& Technology, 2019, 53(9): 5301-5308

123. Li S, Luo J, Wan Y. Regenerable biocatalytic nanofiltration membrane for aquatic micropollutants removal. Journal of Membrane Science, 2018, 549: 120-128

124. Sen D, Sarkar A, Gosling A, Gras S L, Stevens G W, Kentish S E, Bhattacharya P K, Barber A R, Bhattacharjee C. Feasibility study of enzyme immobilization on polymeric membrane: a case study with enzymatically galacto-oligosaccharides production from lactose. Journal of Membrane Science, 2011, 378(1-2): 471-478

125. Abels C, Thimm K, Wulfhorst H, Spiess A C, Wessling M. Membrane-based recovery of glucose from enzymatic hydrolysis of ionic liquid pretreated cellulose. Bioresource Technology, 2013, 149: 58-64 